\title{
Prediction of perinatal outcome with umbilical artery Doppler in IUGR fetuses- a prospective analytical study in a tertiary medical college in Tamilnadu, India
}

\author{
Rajarajeswari R.*, V. Thendral
}

Department of Obstetrics and Gynecology, Thanjavur Medical College, Thanjavur, Tamil Nadu, India

Received: 10 January 2017

Accepted: 08 February 2017

\section{*Correspondence: \\ Dr. Rajarajeswari Rajarajeswari, \\ E-mail: drrrrpanju@gmail.com}

Copyright: (C) the author(s), publisher and licensee Medip Academy. This is an open-access article distributed under the terms of the Creative Commons Attribution Non-Commercial License, which permits unrestricted non-commercial use, distribution, and reproduction in any medium, provided the original work is properly cited.

\begin{abstract}
Background: Umbilical artery Doppler blood flow studies were a better predictor of neonatal outcome than estimated fetal weight alone in intrauterine growth restricted (IUGR) fetuses. Perinatal mortality and morbidity are increased if the umbilical artery Doppler abnormality worsens.

Methods: This study was conducted in Department of Obstetrics and Gynaecology, Thanjavur medical college from August 2015 to August 2016. One hundred singleton pregnancies complicated by IUGR beyond 32 weeks were subjected for Doppler study of umbilical artery. Perinatal outcome in terms of baby outcome, birth weight, early neonatal death, admission in NICU and duration of admission in NICU were analysed.

Results: The main indication of termination of pregnancy was oligohydramnios (70\%). The other causes of termination were $8 \%$ for uncontrolled hypertension and $4 \%$ for post term. $60 \%$ were delivered vaginally and $40 \%$ by lower segment cesarean section. Various indication for LSCS were Non-reactive CTG, fetal distress, severe oligohydramnios and failed induction. $92 \%$ were delivered alive babies and $8 \%$ still born babies. Birth weight of the babies varied from $900 \mathrm{gm}$ to $2.5 \mathrm{Kg}$. But patients with absent or reversed end diastolic flow in umbilical artery Doppler, $80 \%$ of the babies weighed less than $1.5 \mathrm{Kg}$. Perinatal mortality in our study is $19 \%$ which includes $8 \%$ of intrapartum mortality and $11 \%$ of neonatal mortality and perinatal morbidity is $24 \%$. When the diastolic flow in the umbilical artery is, absent or reversed, it is associated with increased perinatal mortality of $80 \%$.

Conclusions: The results of present study clearly demonstrated the efficacy of umbilical artery Doppler in predicting the fetal outcome. To improve the predictive value of this tool, a better method is needed to assess the wellbeing of the IUGR fetuses such as integrated antenatal test which combines BPP and Doppler study employing other vessels.
\end{abstract}

Keywords: IUGR, Perinatal mortality and morbidity, Umbilical artery Doppler study

\section{INTRODUCTION}

Intra Uterine Growth Restriction (IUGR) is defined as estimated fetal weight less than $10^{\text {th }}$ percentile for that gestational age. Growth of the fetus depends on the genetic potential which is determined by maternal and paternal genetic makeup and subsrate supply to the fetus. IUGR is considered when there is failure to achieve this genetic potential. Incidence of IUGR is $3-10 \%$ of all pregnancies upon the diagnostic criteria used. ${ }^{1}$ Chandra and Mathews, reported incidence of IUGR to be $14.1 \% .^{2,3}$ At any gestational age, infants with low birth weight have relatively high morbidity and mortality. ${ }^{3-6}$ Low birth weight babies are prone for fetal demise, birth asphyxia, meconium aspiration, hypoglycaemia, hypothermia, respiratory distress syndrome, necrotizing enterocolitis and intraventricular haemorrhage. There is strong association between IUGR and later development of 
metabolic syndrome comprising of arterial hypertension, coronary artery heart disease, dyslipidemia, visceral obesity, impaired glucose tolerance and Type 2 diabetes mellitus. ${ }^{6}$

IUGR is suspected clinically by abdominal palpation and by the lag in symphysio fundal height. Confirmation of IUGR is done with two dimensional ultrasonogram. When the abdominal circumference is less than $5^{\text {th }}$ percentile or estimated, fetal weight is less than $10^{\text {th }}$ percentile IUGR is diagnosed with certainity. Umbilical artery Doppler blood flow studies were a better predictor of neonatal outcome than estimated fetal weight alone.,

${ }^{10}$ For Doppler velocimetry, fetal vessels namely umblical artery, middle cerebral artery, aortic isthmus, inferior venacava, ductus venosus and umbilical vein are used. Arterial and venous velocimetry changes occur 1 week prior to CTG and BPP changes. It is non-invasive and is capable if depicting the hemodynamic changes occurring in foetuses. Doppler velocimetry not only decides the optimum time of delivery but also the optimum mode of delivery.

\section{Aim of the study}

To study the predictive value of umbilical artery Doppler in IUGR foetuses in relevance to perinatal outcome.

\section{METHODS}

This prospective analytical study was conducted in Department of Obstetrics and Gynaecology, Raja Mirasudar Hospital, Thanjavur Medical College, Tamilnadu, India during the study period August 2015 to August 2016. 100 singleton pregnancies complicated by intrauterine growth restriction beyond 32 weeks were included in the study. Multiple pregnancies, patients with irregular menstrual cycles without dating scan in the first trimester and intra uterine growth restriction complicated by abruption placenta and uterine rupture were excluded from the study.

Toshiba Nemio colour Doppler machine was used for this study. Curvilinear probe with $3.5 \mathrm{MHz}$ was used.

Patients name, age, educational status, previous obstetric outcome, menstrual history, details of last menstrual period and high risk factors in current pregnancy like chronic hypertension, gestational hypertension, renal disease, collagen vascular disease, thyroid disorders, anaemia, heart disease were noted in detail.

If on abdominal palpation growth lag of 4 weeks between gestational age and uterine fundal height is noted, IUGR is suspected. And these patients were subjected for two dimensional ultrasonogram. Fetal biometry including Biparietal diameter (BPD), Head circumference, Abdominal circumference (AC) and Femur length (FL) were noted. Estimated fetal weight is calculated by using
Haddlock formula by an inbuilt software in the ultrasound machine.

Using percentile charts intrauterine growth restricted fetuses were identified when the abdominal circumference is less than $5^{\text {th }}$ percentile and the estimated fetal weight is less than $10^{\text {th }}$ percentile for that gestational age. Once IUGR is diagnosed, all patients are subjected for umbilical artery Doppler velocimetry. Umbilical artery RI, PI and S/D ratio were noted down.

High umbilical artery PI (above the $95^{\text {th }}$ centile for GA) with positive end-diastolic flow, absent end-diastolic flow (AEDF) and reverse end-diastolic flow (REDF) reflect that placental insufficiency is $\geq 50 \%, \geq 70 \%$ and $\geq 90 \%$, respectively. ${ }^{10}$

Reference range of umbilical artery pulsatility index (PI) sampled at free loops from 32 to 41 weeks have been listed in Table $1 .^{11}$

Table 1: Reference range of umbilical artery pulsatility index.

\begin{tabular}{|llll|}
\hline $\begin{array}{l}\text { Gestational } \\
\text { age (weeks) }\end{array}$ & $5^{\text {th }}$ Centile & Mean & $\begin{array}{l}9^{\text {th }} \\
\text { Centile }\end{array}$ \\
\hline 32 & 0.66 & 0.90 & 1.25 \\
\hline 33 & 0.64 & 0.88 & 1.22 \\
\hline 34 & 0.62 & 0.86 & 1.20 \\
\hline 35 & 0.60 & 0.84 & 1.18 \\
\hline 36 & 0.58 & 0.82 & 1.16 \\
\hline 37 & 0.56 & 0.80 & 1.14 \\
\hline 38 & 0.55 & 0.78 & 1.12 \\
\hline 39 & 0.53 & 0.76 & 1.10 \\
\hline 40 & 0.51 & 0.75 & 1.09 \\
\hline 41 & 0.50 & 0.73 & 1.07 \\
\hline
\end{tabular}

Using percentile charts for each index, these IUGR fetuses are categorised into category I, II and III.

\section{Category I}

Umbilical artery Doppler indices less than $95^{\text {th }}$ percentile for that gestational age.

\section{Category II}

Umbilical artery Doppler indices more than $95^{\text {th }}$ percentile for that gestational age. But umbilical artery had forward diastolic flow.

\section{Category III}

Absent diastolic flow or reverse end diastolic flow.

All these patients were kept under surveillance till confinement and were monitored with fetal kick count, CTG, BPP and Doppler velocimetry study. Decision to deliver was taken in situations as 1) gestational age of 37 
weeks, 2) absent end diastolic flow, reverse end diastolic flow, 3) worsening of maternal condition like HELLP, Imminent eclampsia, uncontrolled hypertension 4) oligohydramnios $(\mathrm{AFI}<5)$.

The mode of delivery, birth weight of the baby, APGAR at 1 and 5 minutes, admission in NICU were noted. Still born fetuses and fetuses who dies in early neonatal period were also noted.

\section{RESULTS}

Among the one hundred cases, umbilical artery Doppler indices like pulsatility index, resistance index and systolic diastolic ratio were within $95^{\text {th }}$ percentile in 67 cases, the remaining 33 cases showed abnormal Doppler indices (Table 2).

Table 2: Total number of IUGR cases.

\begin{tabular}{|lll|}
\hline Total number of IUGR cases & 100 & $\%$ \\
\hline Normal Doppler & 67 & 67 \\
\hline Abnormal Doppler & 33 & 33 \\
\hline
\end{tabular}

Table 3: Grading of Doppler abnormalities.

\begin{tabular}{|lll|}
\hline Total number of IUGR cases & 100 & $\%$ \\
\hline Category I & 67 & 67 \\
\hline Category II & 23 & 23 \\
\hline Category III & 10 & 10 \\
\hline
\end{tabular}

Sixty-seven patients belonged to Category 1. Among the 33 in abnormal Doppler group, 23 patients belonged to category II and 10 patients belonged to category III (Table 3).

Most of the patients (53\%) were in the age group of 2327 years. Mean age of the patients were 25.4 years. $64 \%$ of our patients were primigravida, $20 \%$ second gravida, $12 \%$ third gravida and $4 \%$ fourth gravida and above.

Table 4: Gestational age distribution.

\begin{tabular}{|lllll|}
\hline $\begin{array}{c}\text { Gestational } \\
\text { Age (weeks) }\end{array}$ & Category & $\begin{array}{l}\text { Category } \\
\text { I Category }\end{array}$ & $\begin{array}{l}\text { II } \\
\text { II }\end{array}$ \\
\hline $32-34$ & 6 & 3 & 4 & 13 \\
\hline $35-36$ & 14 & 8 & 1 & 23 \\
\hline $37-38$ & 19 & 4 & 3 & 26 \\
\hline $39-40$ & 28 & 8 & 2 & 38 \\
\hline
\end{tabular}

Table 5: Risk factors.

\begin{tabular}{|lcccc|}
\hline Risk factor & $\begin{array}{l}\text { Category } \\
\text { I }\end{array}$ & $\begin{array}{l}\text { Category } \\
\text { II }\end{array}$ & $\begin{array}{l}\text { Category } \\
\text { III }\end{array}$ & $\%$ \\
\hline Nil risk factors & 41 & 10 & 2 & 53 \\
\hline $\begin{array}{l}\text { Gestational } \\
\text { hypertension }\end{array}$ & 20 & 11 & 7 & 38 \\
\hline $\begin{array}{l}\text { Bronchial } \\
\text { asthma }\end{array}$ & 1 & & 1 \\
\hline $\begin{array}{l}\text { Chronic } \\
\text { hypertension }\end{array}$ & 1 & & 1 \\
\hline
\end{tabular}

The distribution of gestational age at which Doppler analysis was done in the study group is shown in Table 4. Gestational age at the time of diagnosis for most patients were in $39-40$ weeks.

Table 6: Indication for termination.

\begin{tabular}{|c|c|c|c|c|}
\hline Indication & Category I & Category II & Category III & $\%$ \\
\hline Oligohydramnios & 51 & 19 & & 70 \\
\hline Term GHT & & 1 & & 1 \\
\hline Uncontrolled hypertension & 5 & 3 & & 8 \\
\hline Post term & 3 & 1 & & 4 \\
\hline HELLP & & 1 & & 1 \\
\hline Imminent eclampsia & 1 & & & 1 \\
\hline Post LSCS & 1 & & & 1 \\
\hline Term & 3 & & & 3 \\
\hline Spontaneous labour & 1 & & & 1 \\
\hline AEDF & & & 7 & 7 \\
\hline REDF & & & 3 & 3 \\
\hline
\end{tabular}

(GHT- Gestational hypertension, HELLP- Hemolysis, elevated liver enzymes, low platelet syndrome.

Table 7: Association of non-reactive NST and oligohydramnios.

\begin{tabular}{|llll|}
\hline Category & Total no. of patients & Non-reactive & Oligohydramnios \\
\hline I & 67 & $5(7.46 \%)$ & $51(76.1 \%)$ \\
\hline II & 23 & $5(21.4 \%)$ & $19(82.6 \%)$ \\
\hline III & 10 & $3(30 \%)$ & $9(90 \%)$ \\
\hline
\end{tabular}


Table 8: Birth weight of the study group.

\begin{tabular}{|lllll|}
\hline $\begin{array}{l}\text { Birth } \\
\text { weight }\end{array}$ & $\begin{array}{l}\text { Category } \\
\text { I }\end{array}$ & $\begin{array}{l}\text { Category } \\
\text { II }\end{array}$ & $\begin{array}{l}\text { Category } \\
\text { III }\end{array}$ & $\%$ \\
\hline $900 \mathrm{gm}-1.5 \mathrm{~kg}$ & 8 & 10 & 8 & 26 \\
\hline $1.6-2 \mathrm{~kg}$ & 17 & 7 & 2 & 26 \\
\hline$>2-2.5 \mathrm{~kg}$ & 42 & 6 & & 48 \\
\hline
\end{tabular}

Table 5 shows the distribution of risk factors in the study group. 53 patients $(53 \%)$ had no risk factor. 38 patients (38\%) had gestational hypertension and one patient had chronic hypertension.
In category I and II the main indication for termination of pregnancy was oligohydramnios (70\%). $8 \%$ was terminated because of uncontrolled hypertension and $4 \%$ were terminated for post term. In the category III group, absent diastolic flow in the umbilical artery was the indication for $7 \%$ and reversal of flow was the indication for $3 \%$ (Table 6).

Increasing severity of Doppler abnormalities were associated with oligohydramnios and non-reactive nonstress test (NST). Table 7 shows the association of Nonreactive NST and oligohydramnios in the study.

Table 9: Neonatal morbidity.

\begin{tabular}{|llll|l|}
\hline Neonatal period & Category I & Category II & Category III & Total number \\
\hline Admission in NICU & $17(25.3 \%)$ & $6(26.1 \%)$ & $1(10 \%)$ & 24 \\
\hline Duration of admission:1-4 days & 12 & 1 & 0 & 13 \\
\hline 5-7 days & 5 & 4 & 0 & 9 \\
\hline$>7$ days & & 1 & 1 & 2 \\
\hline
\end{tabular}

Sixty patients $(60 \%)$ in the study group delivered vaginally and $40 \%$ were delivered by lower segment caesarean section. In category I, LSCS was done for the following indications. Non-reactive CTG (15.62\%), fetal distress $(28.1 \%)$, severe oligohydramnios (25\%) and failed induction $(31.25 \%)$. In category II, the main indication was Non-reactive CTG (71\%) and in category III only one patient was taken up for LSCS and the indication was Non-reactive CTG.

Ninety-two (92\%) patients delivered alive babies and 8 (8\%) patients delivered stillborn babies. $50 \%$ of the category III patients, $10 \%$ category II patients and $1.5 \%$ of category I patient delivered stillborn babies. Birth weight of the babies varied from $900 \mathrm{gms}-2.5 \mathrm{Kgs} .62 .7 \%$ of category I and $28.6 \%$ of category II, baby weight was more than $2 \mathrm{~kg}$. In category III, none of the baby's birth weight was more than $2 \mathrm{~kg}$ and $80 \%$ of babies weighed less than $1.5 \mathrm{~kg}$ (Table 8 ).

There are about $11 \%$ early neonatal death in the NICU. $6 \%$ of category I, $17.3 \%$ of category II and $30 \%$ of category III group had early neonatal death. The causes were attributed to necrotising enterocolitis, Intraventricular haemorrhage and hypoxic ischemic encephalopathy. Overall $80 \%$ of the category III group had poor perinatal outcome either as still birth or as early neonatal death. Neonatal morbidity in terms of admission in the NICU and duration of admission in NICU are shown in Table 9. Totally 35 babies were admitted in NICU $(25.3 \%$ of category I, $26.1 \%$ of category II and $10 \%$ of category III). Varying reason for admission were hypoxic ischemic encephalopathy, respiratory distress, necrotizing enterocolitis, hypoglycaemia, meconium aspiration syndrome and hyperbilirubinemia.

\section{DISCUSSION}

Though IUGR fetuses were diagnosed with two dimensional ultrasonogram, it does not predict the perinatal outcome. Hence these IUGR fetuses were analysed with umbilical artery Doppler and their predictive value for perinatal outcome was analysed (Table 10).

Table 10: Perinatal outcome.

\begin{tabular}{|llll|}
\hline & \multicolumn{3}{l}{ Perinatal outcome } \\
& Adverse & Good & Total \\
\hline Abnormal Doppler & 22 & 11 & 33 \\
\hline Normal Doppler & 21 & 46 & 67 \\
\hline
\end{tabular}

Table 11: Sensitivity and specificity of abnormal Doppler in prediciting adverse outcome in other studies.

\begin{tabular}{|lclll|}
\hline & Sensitivity & Specificity & PPV & NPV \\
\hline $\begin{array}{l}\text { Present } \\
\text { study }\end{array}$ & $51.16 \%$ & $80.70 \%$ & $\begin{array}{l}66.66 \\
\%\end{array}$ & $\begin{array}{l}68.66 \\
\%\end{array}$ \\
\hline $\begin{array}{l}\text { Dicke JM et } \\
\text { al }^{12}\end{array}$ & $40 \%$ & $89 \%$ & $68 \%$ & $72 \%$ \\
\hline $\begin{array}{l}\text { Berkowit et } \\
\text { al }^{13}\end{array}$ & $66.7 \%$ & $62.5 \%$ & $\begin{array}{l}57.1 \\
\%\end{array}$ & $71.4 \%$ \\
\hline $\begin{array}{l}\text { Divion M et } \\
\text { al }\end{array}$ & $49 \%$ & $94 \%$ & $81 \%$ & $77 \%$ \\
\hline $\begin{array}{l}\text { Dhand H et } \\
\text { al }^{15}\end{array}$ & $44 \%$ & $61.5 \%$ & $83 \%$ & $20 \%$ \\
\hline
\end{tabular}

Sensitivity of abnormal Doppler in predicting adverse perinatal outcome: $51.16 \%$ 
Specificity of abnormal Doppler in predicting adverse perinatal outcome: $80.70 \%$.

Positive predictive value (PPV) of abnormal Doppler in predicting adverse perinatal outcome: $66.66 \%$.

Negative predictive value (NPV) of abnormal Doppler in predicting adverse perinatal outcome: $68.66 \%$.

In Table 11 category I patients who had normal Doppler study, the sensitivity of predicting good perinatal outcome was $68.6 \%$. In category II and III patients, the sensitivity of predicting adverse perinatal outcome was $56.5 \%$ and $90 \%$ respectively. As the Doppler diastolic flow decreases, the chance for adverse perinatal outcome increases. In present study, the specificity of abnormal Doppler results exceeded the sensitivity, and the negative predictive value was greater than the positive predictive value. This result is comparable to Dicke JM et al report on small for gestational age fetuses. ${ }^{12}$ The sensitivity, specificity, positive predictive value and negative predictive value of abnormal Doppler in prediciting adverse outcome in Berkowit et al study was $66.7 \%$, $62.5 \%, 57.1 \%$ and $71.4 \%$ respectively. In Divion $\mathrm{M}$ et al study these results were $49 \%, 94 \%, 81 \%$ and $77 \%$ respectively. ${ }^{13,14}$ Dhand $\mathrm{H}$ et al reported the sensitivity and specificity as $44 \%$ and $61.5 \%$ for predicting adverse outcome with umbilical artery Doppler. ${ }^{15}$ Perinatal mortality like still birth, early neonatal death increases as the Doppler abnormality increases.

Mean gestational age when the patients were diagnosed as IUGR was 36.8 weeks. In the study population patients with lesser gestational age $(<32$ weeks) with IUGR were excluded in order to avoid the influence of preterm birth in perinatal morbidity and mortality.

Table 12: Umbilical artery doppler indices and fetal outcome.

\begin{tabular}{|llllll|}
\hline & Sum of squares & Df & Mean square & F & P value \\
\hline Umbilical artery S/D & 83.338 & 2 & 41.919 & 34.234 & $<0.0005$ \\
\hline Umbilical artery RI & 2.076 & 2 & 1.038 & 107.788 & $<0.0005$ \\
\hline Umbilical artery PI & 31.728 & 2 & 15.864 & 208.121 & $<0.0005$ \\
\hline
\end{tabular}

In present study, $47.8 \%$ of category II and $70 \%$ of category III patients had gestational hypertension as a risk factor. Bynn YJ et al, Sharma U et al studies showed gestational hypertension as a predisposing factor for $30 \%$ patients. ${ }^{16,17}$ In Deshmukh A et al study $78.6 \%$ of low diastolic flow patients and $82.35 \%$ of absent /reverse diastolic flow patients were predisposed by hypertensive disorder. ${ }^{18}$

In 68 patients, severe oligohydramnios was considered as an indication for termination of pregnancy. Deshmukh A et al reported that $64.30 \%$ of low diastolic flow group and
$82.35 \%$ of $\mathrm{ADF} / \mathrm{RDF}$ group had oligohydramnios. ${ }^{11}$ In present study $82.6 \%$ of category II and $90 \%$ of category III patients had oligohydramnios. In category III patients $70 \%$ had absent diastolic flow and 30\% had reversal of flow and pregnancy was terminated.

In present study, $60 \%$ delivered vaginally and $40 \%$ were taken up for LSCS. In category I $52.5 \%$ delivered vaginally and $47.5 \%$ delivered by LSCS. In other categories vaginal delivery is the primary mode of delivery. In category II, $69.5 \%$ and in category III, $90 \%$ delivered vaginally.

Table 13: Umbilical artery doppler indices and fetal birth weight.

\begin{tabular}{|ll|llll|}
\hline & Sum of squares & Df & Mean square & F & P value \\
\hline Umbilical artery S/D & 83.338 & 2 & 41.919 & 34.234 & $<0.0005$ \\
\hline Umbilical artery RI & 2.076 & 2 & 1.038 & 107.788 & $<0.0005$ \\
\hline Umbilical artery PI & 31.728 & 2 & 15.864 & 208.121 & $<0.0005$ \\
\hline
\end{tabular}

The mean umbilical artery S/D ratio in category I and II were 2.3 and 4.5 respectively in comparison to Deshmukh A et al study in which these values were 2.53 and 3.82.18 The mean pulsatility index of the study group were $0.8804,1.4687$ and 2.7240 for category I, II and III. In Deshmukh A et al these values corresponded to 0.954,
1.354 and 5.18.18 The mean resistance index in our study group for category I, II and III were $0.5663,0.7800$ and 1.000 .

When umbilical artery Doppler is used for evaluating the fetus, all the three indices namely S/D ratio, pulsatility 
index and resistance index were used. Baby outcome comparing live born and still born were analysed. There is significant difference between and within categories for baby outcome. The $\mathrm{P}$ value $<0.0005$, is significantly significant (Table 12).

Table 14: Perinatal outcome.

\begin{tabular}{|llll|}
\hline & Category I & Category II & Category III \\
\hline No. of patients & 67 & 23 & 10 \\
\hline Still born & 1 & 2 & 5 \\
\hline Early neonatal death & 4 & 4 & 3 \\
\hline Perinatal mortality & $7.5 \%$ & $26.08 \%$ & $80 \%$ \\
\hline Perinatal morbidity & 16 & 7 & 1 \\
\hline Adverse perinatal outcome & $21(31.3 \%)$ & $23(56.52 \%)$ & $9(90 \%)$ \\
\hline
\end{tabular}

When baby outcome in terms of birthweight were analysed with umbilical artery Doppler indices by analysis of variance method, there is significant difference between categories and within category. $\mathrm{P}$ value was $<0.0005$. When the umbilical artery Doppler diastolic flow showed good forward diastolic flow it results in better outcome in terms of birthweight of more than $2 \mathrm{~kg}$. When the umbilical artery diastolic flow worsens from good diastolic flow to absent or reversal of flow, the early neonatal death increases from $6.1 \%$ to $60 \%$. When Anova table is used to analyse the impact of Doppler diastolic flow in the umbilical artery with early neonatal death there is significant difference $(\mathrm{P}<0.0005)$ between categories and within category (Table 13).

Table 15: Perinatal morbidity and mortality in various studies.

\begin{tabular}{|c|c|c|c|c|}
\hline \multirow[b]{2}{*}{ Name of the study } & \multirow{2}{*}{$\begin{array}{l}\text { Category II } \\
\text { Perinatal mortality } \\
\text { (\%) }\end{array}$} & \multicolumn{3}{|l|}{ Category III } \\
\hline & & $\begin{array}{l}\text { Perinatal morbidity } \\
(\%)\end{array}$ & $\begin{array}{l}\text { Perinatal mortality } \\
(\%)\end{array}$ & $\begin{array}{l}\text { Perinatal morbidity } \\
(\%)\end{array}$ \\
\hline Deshmukh et al ${ }^{18}$ & 31 & 72.4 & 64.7 & 88 \\
\hline Bynn YJ et al ${ }^{16}$ & 2.43 & 31.7 & 16.3 & 67.4 \\
\hline Narulla $\mathrm{H}$ et $\mathrm{al}^{19}$ & 50 & 100 & 100 & - \\
\hline Lekhnar BN et al ${ }^{20}$ & 21 & 66 & 100 & - \\
\hline Present study & 26.08 & 30.43 & 80 & 10 \\
\hline
\end{tabular}

The babies admitted in NICU had varying diagnosis namely respiratory distress, hypoxic ischemic encephalopathy, meconium aspiration syndrome, hyperbilirubinemia and necrotizing enterocolitis. The duration of admission in NICU also varied from 1-13 days (Table 9).

Overall perinatal mortality in our study is $19 \%$ which includes $8 \%$ of intrapartum mortality and $1 \%$ of neonatal mortality. Perinatal morbidity is $24 \%$. This is in accordance with Deshmukh et al study where perinatal mortlity and morbidity were $18 \%$ and $49 \%$. Perinatal mortality is higher in absent or reverse diastolic flow group (Table 14).

When the diastolic flow in the umbilical artery is absent or reversed, it is associated with increased perinatal mortality. Mortality rate was $100 \%$ in Narulla $\mathrm{H}$ et al, Lakhar BN et al, Mohamed K et al study. ${ }^{19,20,21}$ Bhatt et al reported $50 \%$ mortality. ${ }^{22}$ In this current study $80 \%$ perinatal mortality occurred in category III (Table 15).

In category II, the perinatal mortality was $26.08 \%$. Unless the change in the diastolic flow of the umbilical artery was followed up in category II the mortality rate would have reached higher rate as in absent or reversed group.

In category I, above said studies were in favour of good perinatal outcome with $100 \%$ negative predictive value, in present study these patients also had adverse perinatal outcome in both mortality $(7.5 \%)$ and morbidity $(23.9 \%)$. In Figueras $\mathrm{F}$ et al study, he said that normal antenatal Doppler cannot be taken as an indicator of good perinatal outcome in pregnancies with IUGR fetuses. ${ }^{23}$ Cochrane database systematic review (2000) in high risk pregnancies concluded that, the use of Doppler ultrasonogram in high risk pregnancies appear to improve a number of obstetric outcome and appears promising in helping to reduce perinatal death. ${ }^{24}$ 
The results of the present study clearly demonstrated the efficacy of umbilical artery Doppler in predicting the fetal outcome. To improve the predictive value of this tool, a better method is needed to assess the well-being of IUGR fetuses such as integrated antenatal test which combines BPP and Doppler study employing other vessels.

\section{CONCLUSION}

Identifying intra uterine growth restricted fetuses due to uterplacental insufficiency is helpful in planning the antenatal fetal surveillance. Umbilical artery Doppler study identify the changes in the umbilical artery which in turn predicts the resistance offered at the placenta. When the umbilical artery diastolic flow become absent or reversed it is associated with increased perinatal mortality and morbidity. Hence Umbilical artery Doppler is one of the effective tool for doing antenatal fetal surveillance in IUGR fetuses.

Funding: No funding sources

Conflict of interest: None declared

Ethical approval: The study was approved by the Institutional Ethics Committee

\section{REFERENCES}

1. Seeds JW. Impaired fetal growth: definition and clinical diagnosis. Obstet Gynecol. 1984;64(3):30310.

2. Chandra S, Mathews SC. Perinatal morbidity and mortality in low birthweight babies. J obstet Gynaecol India. 2003:53(3):237.

3. Bhide, Arulkumaran, Damania, Daftary. Arias' Practical guide to high-risk pregnancy and delivery: A South Asian perspective, $4^{\text {th }}$ ed. 2015:88-103.

4. McIntire DD, Bloom SL, Casey BM, Leveno KJ. Birth weight in relation to morbidity and mortality among newborn infants. New England J Med. 1999;340(16):1234-8.

5. Cemace Perinatal Mortality 2008. London, UK: Centre for Maternal and Child Enquiries; 2010.

6. Briana DD, Malamitsi-Puchner A. Intrauterine growth restriction and adult disease: the role of adipocytokines. Eur J Endocrinol. 2009;160(3):33747.

7. Ott WJ. Intrauterine growth restriction and Doppler ultrasonography. J Ultrasound Med. 2000;19(10):661-5.

8. Bhide A, Acharya G, Bilardo CM, Brezinka C, Cafici D, Hernandez-Andrade E, et al. ISUOG practice guidelines: use of Doppler ultrasonography in obstetrics. Ultrasound in obstetrics and gynecology: In Soc Ultrasound Obstet Gynecol. 2013;41(2):233.

9. Morris RK, Malin G, Robson SC, Kleijnen J, Zamora J, Khan KS. Fetal umbilical artery Doppler to predict compromise of fetal/neonatal wellbeing in a high-risk population: systematic review and bivariate meta-analysis. Ultrasound Obste Gynecol. 2011;37(2):135-42.

10. Alfirevic Z, Stampalija T, Gyte GM. Fetal and umbilical Doppler ultrasound in high-risk pregnancies. cochrane Database Syst Rev. 2010;(1):CD007529.

11. Acharya G, Wilsgaard T, Berntsen GK, Maltau JM, Kiserud T. Reference ranges for serial measurements of blood velocity and pulsatility index at the intraabdominal portion, and fetal and placental ends of the umbilical artery. Ultrasound Obstet Gynecol. 2005;26(2):162-9.

12. Dicke JM, Huettner P, Yan S, Odibo A, Kraus FT. Umbilical artery doppler indices in small for gestational age fetuses' correlation with adverse outcomes and placental abnormalities. J Ultrasound Med. 2009;28(12):1603-10.

13. Berkowitz Gs, Mehalek Ke, Chitkara U, Rosenberg J, Cogswell C, Berkowitz Rl. Doppler umbilical velocimetry in the prediction of adverse outcome in pregnancies at risk for intrauterine growth retardation. Obstet Gynecol. 1988;71(5):742-6.

14. Divon MY, Guidetti DA, Braverman JJ, Oberlander E, Langer O, Merkatz IR. Intrauterine Growth retardation-a prospective study of the diagnostic value of real-time sonography combined with umbilical artery flow velocimetry. Obstet Gynecol. 1988;72(4):611-4.

15. Dhand H, Kansal HK, Dave A. Middle cerebral artery Doppler indices better predictor for fetal outcome in IUGR. J Obstet Gynecol India. 2011;61(2):166-71.

16. Byun YJ, Kim HS, Yang JI, Kim JH, Kim HY, Chang SJ. Umbilical artery Doppler study as a predictive marker of perinatal outcome in preterm small for gestational age infants. Yonsei Med J. 2009;50(1):39-44.

17. Urmila S, Beena B. Triple vessel wave pattern by Doppler studies in normal and high risk pregnancies and perinatal outcome. J Obstet Gynecol India. 2010;60(4):312-6.

18. Deshmukh A, Neelu S, Suneeta G. Significance of umbilical artery Doppler velocimetry in the perinatal outcome of the growth restricted fetuses. J Obstet Gynecol. 2010;60(1):38-43.

19. Narulla H, Kapila AK, Kaur MM. Cerebral and umbilical arterial blood flow velocity in normal and growth retarded pregnancy. J Obstet Gynecol India. 2009;59(1):47-52.

20. Lakhkar BN, Rajagopal KV, Gourisankar PT. Doppler prediction of adverse perinatal outcome in PIH and IUGR. Indian Radiol Imag. 2006;16(1):109.

21. Khalid M, Wahab S, Khalid VK, Haroon S, Sabzposh NA. Doppler indices in prediction of fetal outcome in hypertensive pregnant women. Nepal J Obstet Gynaecol. 2015;6(1):28-34.

22. Bhatt CJ, Arora J, Shah MS. Role of color Doppler in pregnancy induced hypertension (a study of 100 cases). Indian J Radiol Imag. 2003;13(4):417. 
23. Figueras F, Eixarch E, Gratacos E, Gardosi J. Predictiveness of antenatal umbilical artery Doppler for adverse pregnancy outcome in small-forgestational-age babies according to customised birthweight centiles: population-based study. BJOG: Int J Obstet Gynaecol. 2008;115(5):590-4.

24. Neilson JP, Alfirevic Z. Doppler ultrasound for fetalassessment in high risk pregnancies. Cochrane

Cite this article as: Rajarajeswari R, Thendral V. Prediction of perinatal outcome with umbilical artery Doppler in IUGR fetuses- a prospective analytical study in a tertiary medical college in Tamilnadu, India. Int J Reprod Contracept Obstet Gynecol 2017;6:1097-104.

Database Syst Rev. 2000;(2):CD 000073. 